\title{
Physio-Biochemical and Genetic Exploration for Submergence Tolerance in Rice (Oryza sativa L.) Landraces with Special References to Sub1 Loci
}

\author{
Sayani Goswami1', Reha Labar1, Anupam Paul', Malay Kumar Adak ${ }^{3}$, Narottam Dey ${ }^{*}$ \\ ${ }^{1}$ Department of Biotechnology, Visva-Bharati, Santiniketan, India \\ ${ }^{2}$ Agricultural Training Centre, Fulia, India \\ ${ }^{3}$ Department of Botany, Plant Physiology and Plant Molecular Biology Research Unit, University of Kalyani, \\ Kalyani, India \\ Email: goswamisayani@gmail.com, rehalabar@yahoo.com, anupampaul99@gmail.com, \\ mkadak09@gmail.com, ${ }^{*}$ narottam.dey@visva-bharati.ac.in
}

Received 15 May 2015; accepted 4 August 2015; published 7 August 2015

Copyright (C) 2015 by authors and Scientific Research Publishing Inc.

This work is licensed under the Creative Commons Attribution International License (CC BY).

http://creativecommons.org/licenses/by/4.0/

(c) (i) Open Access

\section{Abstract}

In the present study a group of four indigenous and less popular rice genotypes (Meghi, Panibhasha, Jabra and Sholey) reported by growers as submergence tolerant lines from flood prone areas of south Bengal were explored through study of nodal anatomy, physio-biochemical screening under submergence and genotyping with submergence tolerance linked rice microsatellite loci (RM loci). To identify the different allelic forms of different Sub1 compnents (Sub1A, Sub1B and Sub1C) among the studied lines, the genomic DNA of individual genotypes was amplified with three ethylene response factor like genes from Sub1 loci, located on rice chromosome 9. From the different physio-biochemical experiments performed in this investigation, it has been shown that Meghi and Jabra are the two probable potent genotypes which share common properties of both submergence tolerant and deep water nature whereas rest two genotypes (Sholey and Panibhasha) behave like typical deep water rice. The submergence tolerance property of Meghi was also confirmed from submergence tolerance linked SSR based genotyping by sharing with FR13A for some common alleles as reflected in fingerprint derived dendrogram. The rest of the genotypes shared a number of alleles and were included in a separate cluster. The common behaviour of Meghi and FR13A under submergence was also confirmed from genetic study of Sub1 loci through sharing of some common alleles for three Sub1 components (Sub1A, Sub1B and Sub1C loci). One SSR loci (RM 285) was identified as a potent molecular marker for submergence tolerance breeding programme involving these two selected rice lines (Meghi and Jabra) as donor plant through marker assisted ${ }^{*}$ Corresponding author. 
selection.

Keywords

Rice, Submergence Tolerance, Rice Microsatellite, Sub1 Loci, Marker Assisted Breeding

\section{Introduction}

Submergence is the third most important abioitic stress, hindering rice productivity in eastern India [1]. Though rice is a crop that requires flooded and irrigated condition for cultivation, most of the rice varieties are susceptible to flooding if the water stagnates keeping the plants submerged under water for more than seven days [2] causing leaf or stem elongation, leaf rotting, loss of dry mass and also lodging after the flood water recedes [3]. According to Sarkar et al. [1], "submergence tolerance is a metabolic adaptation in response to anaerobiosis that enables cells to maintain their integrity so that the plant survives hypoxia without major damages". Submergence tolerance includes a number of anatomical (formation of higher aerenchyma tissue in nodal region), physiological (more shoot elongation) and biochemical (inhibition of chlorophyll degradation, less utilization of storage carbohydrates, and increased activity of antioxidative enzymes) adaptations [4]-[10]. A major QTL loci responsible for submergence tolerance was mapped to chromosome 9, designated as Submergence1 (Sub1), reported to be accounting for about $70 \%$ of the phenotypic variation under submergence [11]. This locus includes three similar genes that encode ethylene response factor (ERF)/ethylene-responsive element binding (EREB) proteins/Apetala2 - type transcription factor domain: Sub1A, Sub1B and Sub1C [12]. Sub1B and Sub1C are present in the $S u b 1$ region of all rice cultivars whereas the presence of $S u b 1 A$ is varying [12] [13]. Over expression of Sub1A-1 in a submergence-intolerant $O$. sativa ssp. japonica conferred enhanced tolerance to submergence to the plants, down regulation of Sub1C and up regulation of Alcohol dehydrogenase 1 (Adh1), indicating that Sub1A-1 was a primary determinant of submergence tolerance [12] [13]. Development of submergence tolerant rice genotypes is very essential for reducing the yield loss in lowland and flood prone rice growing areas. Till today only a single rice landrace (FR13A) has been utilized in submergence tolerance breeding programme for which a major QTL (Sub1) has been transferred to a number of high yielding improved lines for development of submergence tolerant HYVs (e.g. Swarna-Sub1, IR64-Sub1, Samba Mahsuri-Sub1, etc.) [14]-[17]. The only limitation with these inbred lines is short plant type which makes them unsuitable for medium to deep low land areas where water depth may reach up to $100 \mathrm{~cm}$ or more and persist for more than one month [1] [18]-[21]. It has been shown that few traditional deep water low yielding rice lines are still cultivated in extremely deep water lowland areas by poor marginal farmers where none of the improved lines can grow [14]. Though eastern India had harboured a hand full of such rice land races, during and after green revolution, most of them were prematurely replaced by HYVs prior to any experimentation and possible utilization in breeding [22]. Experimentation and utilization of remaining few such lines which are limited to a narrow marginal rice growing regions may prove to be one of the most effective strategies for possible utilization of the different beneficiary traits available within them [15] [23]. Keeping this as the objective, a good number of low yielding, less popular, submergence tolerant rice lines were collected from low land flood prone areas of south Bengal, for which no earlier information was available except on their growth and habitat from their respective growers. In this present study four such selected lines were experimented for their submergence tolerance properties through physio-biochemical and genetic analysis for their possible utilization in marker assisted breeding programme. Another objective of the present study was to find out some polymorphic molecular markers between the selected submergence tolerant line (donor plant) and a high yielding submergence sensitive rice line (recurrent plant) which would be used to select out the appropriate inbred lines in breeding programme.

\section{Materials and Methods}

\subsection{Plant Materials}

A good number of indigenous rice lines were collected from the farmer's field of low land flood prone areas of south Bengal (Figure 1) of which four genotypes were selected based on the available information on growth 
and habitat from local farmers of respective rice growing regions. The detailed description of these lines is presented in Table 1. FR13A, the most well experimented submergence tolerant line utilized in submergence tolerance breeding programme was included in this experiment as reference genotype. One high yielding, submergence susceptible rice line (IR36) which has been used as high yielding recurrent parent in a number of international breeding programme and also the most extensively cultivated high yielding line of West Bengal at present with high consumer preferences was included in this study as reference line for marker based genotyping. As this line is very popular and well characterized, only marker based genotyping was done to find out the polymorphic markers between the studied varieties and IR36.

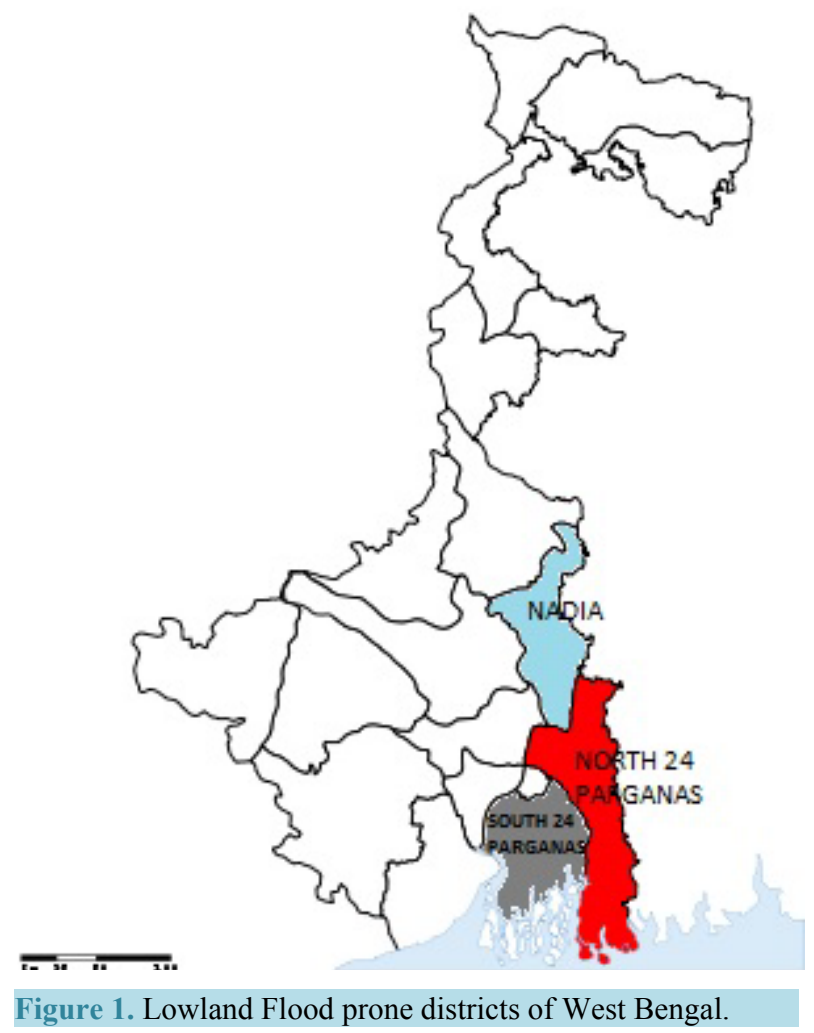

Table 1. Details of landraces used in this study.

\begin{tabular}{|c|c|c|c|}
\hline Sl. No. & Acc. No. & Genotype & Specific Note \\
\hline 1. & VB69 & FR13A & $\begin{array}{l}\text { Highly submergence tolerant rice landrace, for the first time reported from the rice field of Orissa in } \\
\text { 1950's and have been included in a number of submergence tolerant breeding programme } \\
\text { as donor to develop a number of high yielding submergence tolerant hybrid lines. } \\
\text { Grain medium long with distinct awn. Kernel reddish brown in color and bold in shape. }\end{array}$ \\
\hline 2. & VB196 & Meghi & $\begin{array}{c}\text { Submergence tolerant traditional rice line of south Bengal, deep water rice and can grow with } \\
\text { increase of water level as reported by growers, having grain length of medium length with bold, } \\
\text { brown kernel. Good for popped rice preparation. }\end{array}$ \\
\hline 3. & VB199 & Sholey & $\begin{array}{l}\text { Submergence tolerant indigenous rice line of south Bengal can tolerate } 5-15 \text { days of submergence } \\
\text { with medium long grain and kernel which is brown in color. Straw may be up to } 10-22 \mathrm{ft} \text { long. }\end{array}$ \\
\hline 4. & VB231 & Panibhasha & Submergence tolerant rice line of south Bengal with long grain length and medium shaped, brown kernel. \\
\hline 5. & VB239 & Jabra & $\begin{array}{l}\text { Submergence tolerant indigenous rice line of south Bengal can tolerate } 5-15 \text { days of submergence with } \\
\text { medium long grain and kernel, which is brown in color. Straw may be up to } 10-22 \mathrm{ft} \text { long. Presence } \\
\text { of anthocyanin pigmentation can be seen on the lower portion of the stem of mature plants. }\end{array}$ \\
\hline 6. & VB9 & IR36 & $\begin{array}{l}\text { Submergence susceptible, high yielding improved, semi dwarf rice line developed during the green } \\
\text { revolution, with maturation time of } 105 \text { days and presently cultivated in most of } \\
\text { the upland rice fields of eastern India. Produces slender grain. }\end{array}$ \\
\hline
\end{tabular}




\subsection{Agromorphological Characterization}

Initial characterization of the studied lines was done for grain and kernel dimension and their weight for proper identification of the selected lines.

\subsection{Anatomical Study}

A comparative study on amount and distribution of aerenchyma tissues between normal and submerged plant of each lines were done for the same nodal region. Thin cross sections, prepared from the respective nodal portion were stained properly with safranin and examined under compound microscope.

\subsection{Physiological Characterization}

For physiological characterization germination potential, seedling vigor and seedling growth of each studied lines were recorded under submerged condition. All the experiments were repeated twice. For study of germination potential, 10 healthy seeds of each selected rice genotypes were surface sterilized with $0.1 \%$ mercuric chloride and kept under water in test tubes with control set for each lines. Germination potential (percentage) was calculated using the ratio (No. of seeds germinated/No. of seeds kept for germination) multiplied by 100 . Seedling vigor of the experimental varieties was tested using test tube method as described [24]. Seedling vigor index was calculated according to the formula as mentioned [25]. Five healthy seeds of each studied genotypes were first surface sterilised with freshly prepared $0.01 \%(\mathrm{w} / \mathrm{v})$ mercuric chloride and then soaked in cotton for germination. Seven days old seedlings were fully submerged for duration of seven days under $90 \mathrm{~cm}$ of water. After seven days, the plants were desubmerged and kept seven days of duration for hardening. A control set was maintained under nonsubmerged condition for same duration. Anatomical study and biochemical estimation were done 21 days after germination. Shoot length of the seedling were measured at two days interval during the period of submergence and at the time of hardening after desubmergence.

\subsection{Biochemical Studies}

Comparative estimations for soluble and insoluble carbohydrate, total chlorophyll and protein content were done from mature leaf tissue of submerged and nonsubmerged plants for each genotype. Carbohydrate estimation was done using anthrone reagent following a published protocol [26] and chlorophyll estimation was done following Arnon's method using Arnon's formula [27].

\subsection{Genetic Analysis}

Genetic analysis was done through genotyping with submergence tolerance linked microsatellite loci and allelic diversity analysis for the Sub1A loci among the studied lines. The genotype IR36 was included in marker based genotyping but not in the study of allelic diversity for the Sub1A loci. Genomic DNA was isolated following a pre-standardized protocol [28] [29] of our laboratory. To assess the genetic relationship amongst the rice genotypes, SSR markers are found to be most advantageous [30] and informative. Genetic relationship among the five studied rice genotypes was assessed for five reported tightly linked SSR markers (RM 219, RM 316, RM 464A, RM 444 and RM 285) mapped to Sub1 QTL on rice chromosome 9 [12] [16] [19]. Detail information of the map position of five used SSR markers are presented in Figure 2 (after taking kind permission from the workers [31]). This map was constructed using three mapping populations (ZS97, WYJ, DL208 and H94). The detailed information of these markers and their respective sequences were collected from Gramene website (http://www.gramene.org), a freely available website for cereals and presented in Table 2. To study the allelic diversity in $S u b 1$ loci (the detail information of $S u b 1$ is given in Table 3) among the studied lines, primers were designed from three components of Sub1 loci $(S u b 1 A, S u b 1 B$ and Sub1C) (Table 4). Primer sequences were subjected to BLAST analysis in Gramene database (www.gramene.org) to find out the possible sequence similarity in rice genome and final confirmation was done through in silico PCR targeting the respective DNA sequences using a freely available web resource (http://insilico.ehu.es) (Table 5). The primer sequences were synthesized from Integrated DNA Technology (IDT, USA).

\subsection{PCR Amplification}

PCR amplification was done following an earlier reported protocol [28] from our laboratory using a thermal 


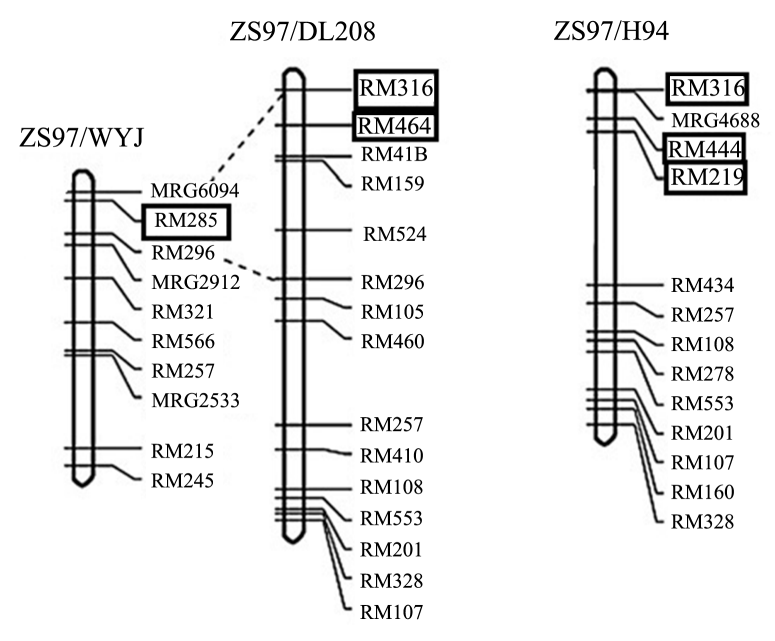

Figure 2. Location of the five selected SSR loci on rice chromosome 9 used in this study (Peng et al. 2014).

Table 2. Details of RM markers used in this study.

\begin{tabular}{|c|c|c|c|c|c|}
\hline \multirow{2}{*}{ Sl. No. } & \multirow{2}{*}{ RM Marker } & \multirow{2}{*}{ Repeat Motif } & \multicolumn{2}{|c|}{ Primer Sequence } & \multirow{2}{*}{ Chr. No. } \\
\hline & & & Forward & Reverse & \\
\hline 1 & RM 219 & (CT)17 & 5'CGTCGGATGATGTAAAGCCT3' & 5'CATATCGGCATTCGCCTG 3' & 9 \\
\hline 2 & RM 316 & $\begin{array}{c}\text { (GT) } 8(\mathrm{TG}) 9 \\
(\mathrm{TTTG}) 4(\mathrm{TG}) 4\end{array}$ & 5'CTAGTTGGGCATACGATGGC3' & 5'ACGCTTATATGTTACGTCAAC3' & 9 \\
\hline 3 & $\mathrm{RM} 464 \mathrm{~A}$ & (AT) 21 & 5'AACGGGCACATTCTGTCTTC3' & 5'TGGAAGACCTGATCGTTTCC3' & 9 \\
\hline 4 & RM 444 & (AT) 12 & 5'GCTCCACCTGCTTAAGCATC3' & 5'TGAAGACCATGTTCTGCAGG3' & 9 \\
\hline 5 & RM 285 & $(\mathrm{GA}) 12$ & 5'CTGTGGGCCCAATATGTCAC3' & 5'GGCGGTGACATGGAGAAAG3' & 9 \\
\hline
\end{tabular}

Table 3. Details of Submergence1 loci.

\begin{tabular}{ccccc}
\hline Sl. No. & Name & Description & Position & Source \\
\hline 1 & DQ011598.1 & Submergence-1A & Chr09:2308684..2309239 & NCBI, Ensembl Plant \\
2 & tr|B1PI82|B1PI82_xORYNI & Submergence-1B & chr09:6404750..6405950 & RAP-DB \\
3 & tr|B1PI84|B1PI84_ORYNI & Submergence-1C & chr09:6388958..6389653 & RAP-DB \\
\hline
\end{tabular}

Table 4. Details of markers specifically linked with Sub1 loci used in this study.

\begin{tabular}{|c|c|c|c|c|}
\hline \multirow{2}{*}{ Sl. No. } & \multirow{2}{*}{$\begin{array}{c}\text { Gene Specific } \\
\text { Marker }\end{array}$} & \multicolumn{2}{|c|}{ Primer Sequence } & \multirow{2}{*}{ Chr. No. } \\
\hline & & Forward & Reverse & \\
\hline 1 & $\operatorname{Sub} 1 A$ & 5'CAGGAATAAGTAGGCACATCA3' & 5'GGACCAAGAACAAAGTCAAA3' & 9 \\
\hline 2 & $\operatorname{Sub} 1 B$ & 5'ATGGAGACGACCACAGAG3' & 5'GCAGCACTCCAGCAGTAT3' & 9 \\
\hline 3 & Sub1C & 5'GATCCGTGGTAGTGACAAG3' & 5'AGCAGCACTCGATGAGTAT3' & 9 \\
\hline
\end{tabular}

Table 5. Comparison between molecular weights of products of in silico PCR and wet lab PCR.

\begin{tabular}{cccc}
\hline Sl. No. & Gene Name & Product Size Estimated in Silico PCR (bp) & Product Size through Wet Lab PCR (bp) \\
1 & Sub1A & 715 & $956.09(\mathrm{a} 1), 747.65(\mathrm{a} 2)$ \\
2 & Sub1B & 453 & $1400(\mathrm{~b} 1)$ \\
3 & Sub1C & 434 & $1330(\mathrm{c} 1), 534.6(\mathrm{c} 2)$ \\
\hline
\end{tabular}


cycler (M. J. Research, MC 013130) in $25 \mu \mathrm{l}$ of reaction mixture containing $100 \mathrm{ng}$ of genomic DNA, $2.5 \mu 1$ of 10X Taqbuffer, $1.0 \mu \mathrm{l}$ of $50 \mathrm{mM} \mathrm{MgCl}_{2}, 0.25 \mu \mathrm{l}$ of $2.5 \mathrm{mM}$ dNTPs, $1 \mu \mathrm{l}$ each of the forward and reverse primers $(10 \mathrm{pmol} / \mu \mathrm{l}), 0.1 \mu \mathrm{l}$ of $5 \mathrm{U} / \mu \mathrm{l}$ Taq-polymerase. The thermal cycling profile for the first step was $95^{\circ} \mathrm{C}$ for $5 \mathrm{~min}$. For the next 35 cycles the temperature regime was $94^{\circ} \mathrm{C}$ for $1 \mathrm{~min}, 50^{\circ} \mathrm{C}$ for $1 \mathrm{~min}$ and $72^{\circ} \mathrm{C}$ for $2 \mathrm{~min}$, final extension at $72^{\circ} \mathrm{C}$ for $10 \mathrm{~min}$. The annealing temperature of each set of PCR reaction was changed according $\mathrm{Tm}$ value of individual primer set.

\subsection{Polymorphism Screening and Allelic Diversity Analysis}

For SSR based polymorphism screening among the studied genotypes, the amplified products were resolved in 6\% native polyacrylamide gel following the standard protocol [32]. The molecular weight of the amplified DNA bands from the different rice genotypes was determined with help of a $100 \mathrm{bp}$ DNA ladder, included in the gel as size marker with the help of image analysis software (AlphaEaseFC 4.0, USA). Individual alleles (in form of differences in molecular weight of the amplified product for individual SSR loci) for each microsatellite loci were scored to prepare a 1/0 matrix based on presence (1) or absence (0) of a particular band. A pair-wise similarity coefficient matrix between all possible pairs of the rice genotypes were calculated from the $1 / 0$ matrix using statistical software (SPSS 16.0) and a dendrogram was constructed using average linkage between groups using STATISTICA software. To find out the informativeness of individual markers, the Polymorphism information content (PIC) of each marker loci was calculated by the simplified formula $\mathrm{PIC}_{i}=1-\sum P_{i j}^{2}$, Where, $i=$ 1 to $n$ and $P_{i j}$ is the frequency of $j^{\text {th }}$ allele for the $i^{\text {th }}$ band scored for a particular marker loci [33]. For IR36 the different allelic forms of each SSR loci were only determined, but not included in further analysis. The amplified products, obtained from the individual Sub1 loci specific primers across the studied genotypes were resolved in $1.5 \%$ agarose gel and the different allelic (variation in molecular weight) forms of each individual Sub1 loci were determined.

\section{Results}

\subsection{Agromorphological Studies}

Grain and kernel morphology (size and shape) of the studied lines are presented in Figure 3. Grain and kernel dimension were categorized (Table 6) according to SES (Standard Evaluation System, IRRI, Philippines). For elaborate characterization 100 grain and kernel weights were also recorded and presented in Table 6.

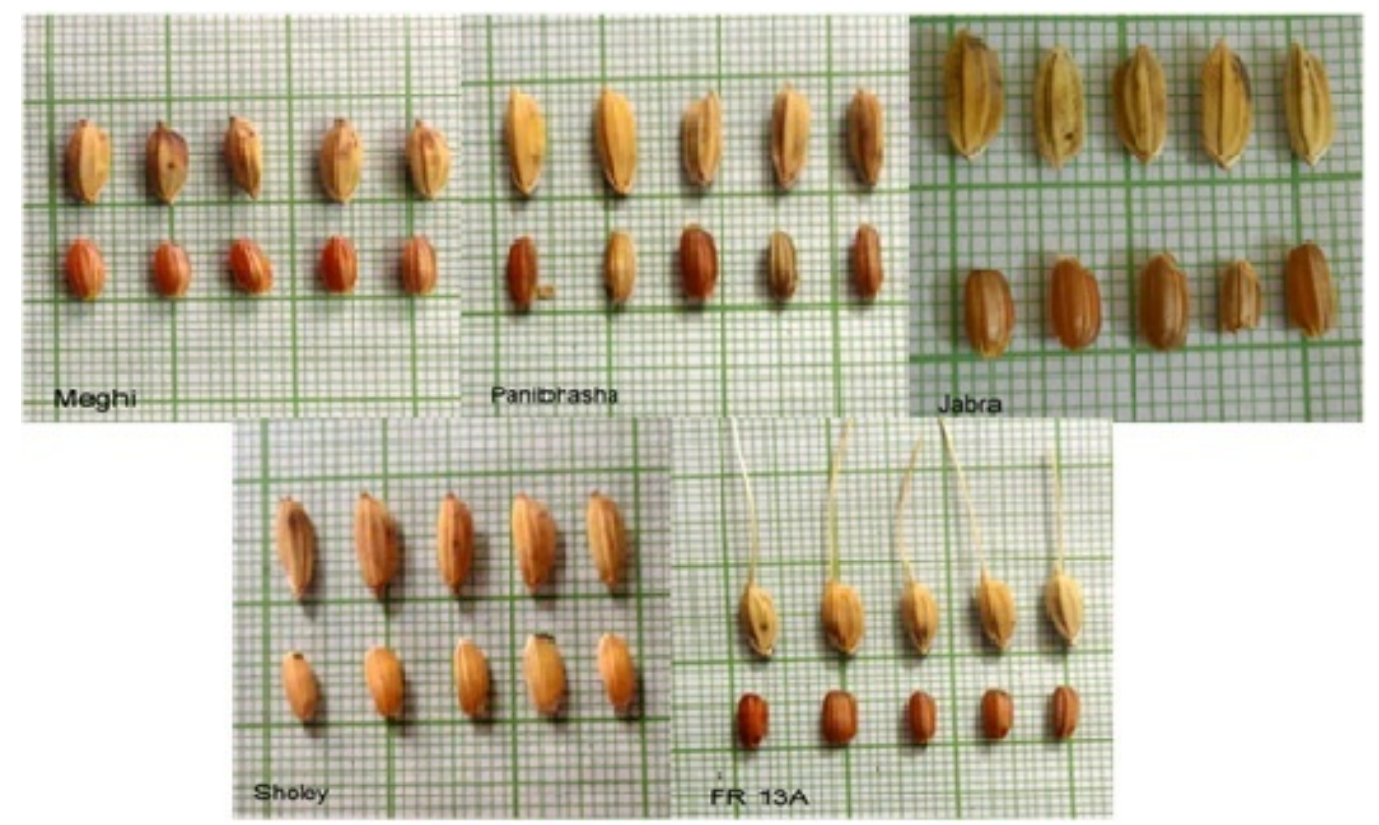

Figure 3. Grain and kernel dimension of the studied rice lines. 


\subsection{Anatomical Studies}

Among the studied lines, Meghi showed maximum difference in aerenchyma tissue formation between the control and submerged plants in comparison to other lines. The submerged plants showed more amount of aerenchyma tissues (Figure 4) with air channels of relatively bigger in size.

\subsection{Physiological Studies}

Under submerged condition all the varieties germinated with varied potentiality. Jabra showed highest germination percentage (100\%) (Figure 5(a)) among all the studied lines under submerged condition within seven days of treatment. Jabra also showed highest seedling vigor among the studied lines. The graphical representation of seedling vigor is shown in Figure 5(b). From the growth pattern analysis during submergence it was observed (Figure 5(c)) that Meghi checked the growth during submergence which is very much similar to FR13A also consistent with the submergence tolerant property. Whereas Jabra, Sholey and to some extent Panibhasha showed a continuous increase in shoot length during submergence exemplifying the submergence escaping property.

\subsection{Biochemical Studies}

Total chlorophyll and total protein content of all the studied rice lines are represented in Figure 5(d) and Figure 5(e) respectively. Of all the studied lines Meghi showed highest reduction in total chlorophyll as well as total protein content during submergence. Meghi, Panibhasha and Sholey showed significant increase in soluble carbohydrate content whereas Jabra showed decrease (5\%) in soluble carbohydrate content under submergence. All of the rice lines except Jabra showed significant decrease in the amount of insoluble carbohydrate content. Both soluble and insoluble carbohydrate profiles are represented graphically in Figure 6(a) and Figure 6(b) respectively.

\subsection{Genetic Analysis}

Dendrogram (Figure 7) resulted out from the genotypic profiling showed that Meghi and FR13A are included in

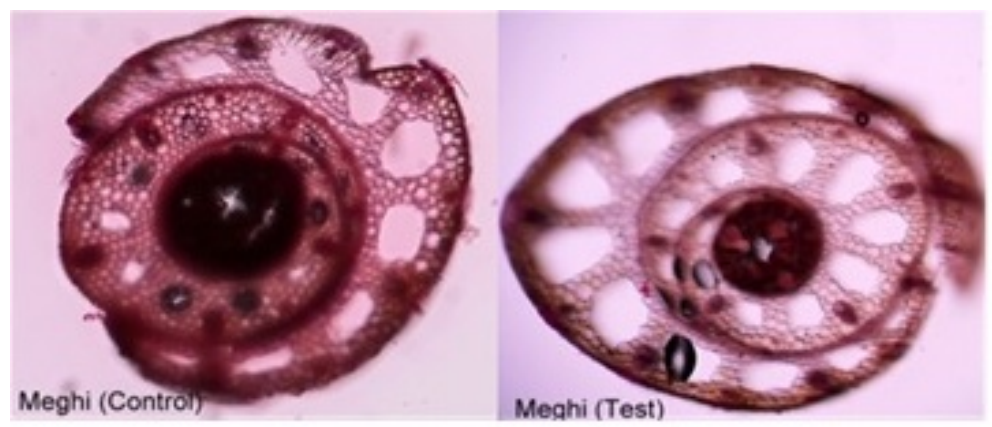

Figure 4. Cross section across the nodal region of rice line (Meghi) in both submerged (test) and non submerged (control) condition.

Table 6. Agromorphological data.

\begin{tabular}{|c|c|c|c|c|c|c|c|c|c|}
\hline \multirow[b]{2}{*}{ Sl. No. } & \multirow{2}{*}{ Acc. No. } & \multicolumn{4}{|c|}{ Grain } & \multicolumn{4}{|c|}{ Kernel } \\
\hline & & $\begin{array}{l}\text { Length } \\
(\mathrm{mm})\end{array}$ & $\begin{array}{l}\text { Breadth } \\
(\mathrm{mm})\end{array}$ & Length/Breadth & $\begin{array}{l}100 \text { Grain } \\
\text { Wt. (gm.) }\end{array}$ & $\begin{array}{l}\text { Length } \\
(\mathrm{mm})\end{array}$ & $\begin{array}{l}\text { Breadth } \\
(\mathrm{mm})\end{array}$ & Length/Breadth & $\begin{array}{l}100 \text { Kernel } \\
\text { Wt. (gm.) }\end{array}$ \\
\hline 1 & VB196 & 8.28 & 3.72 & 2.2258 & 15.0 & 6.06 & 3.3 & 1.8363 & 12.6 \\
\hline 2 & VB231 & 9.3 & 3.6 & 2.5833 & 11.1 & 6.6 & 2.84 & 2.3239 & 11.2 \\
\hline 3 & VB239 & 7.96 & 2.96 & 2.6891 & 13.4 & 5.4 & 2.6 & 2.0769 & 9.8 \\
\hline 4 & VB199 & 8.44 & 3.1 & 2.7225 & 10.9 & 6.1 & 2.9 & 2.1034 & 10.7 \\
\hline 5 & VB69 & 8 & 3.42 & 2.3391 & 13.4 & 6.0 & 2.46 & 2.4390 & 8.4 \\
\hline
\end{tabular}




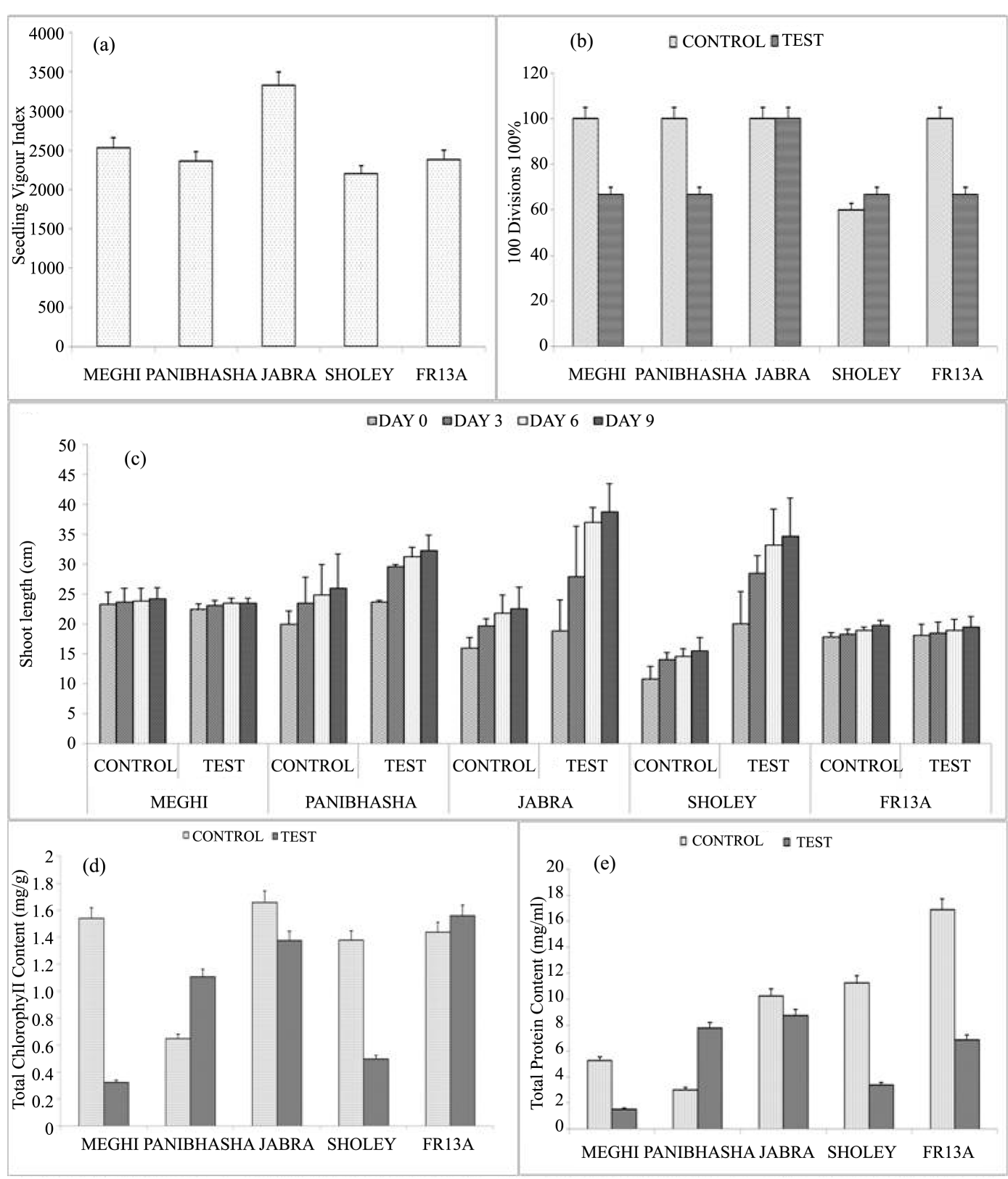

Figure 5. Graphical presentation (a) Seedling Vigor Index (b) Germination percentage (c) Shoot growth (d) Total chlorophyll content and (e) Total protein content in studied rice lines in submerged (test) and non submerged (control) condition.

first cluster whereas Jabra, Sholey and Panibhasha shared the second one. PIC (Table 7) values of all the studied SSR markers were calculated which showed highest (0.96) value in RM464A followed by rest of the markers with PIC value ranging from 0.8 to 0.93 .

\subsection{Allelic Diversity Analysis for Sub1 Loci among the Studied Genotypes}

DNA amplification profile (Figure 8) generated from three components of Sub1 loci (Sub1A, Sub1B and Sub1C) for the studied lines showed presence of common alleles $\left(a_{1}, b_{1}, c_{1}\right.$ as well as $\left.c_{2}\right)$ between Meghi and FR13A. On the other hand Panibhasha and Jabra, sharaed the presence of $\mathrm{a}_{2}$ allele of $S u b 1 A$ loci and $\mathrm{c}_{2}$ allele of Sub1C loci. Meghi also shared with the earlier genotypes (Panibhasha and Jabra) the presence of another common allele $\left(\mathrm{a}_{2}\right)$ of $S u b 1 A$ loci. The $S u b 1 A$ locus of Meghi is very interesting because of the fact that Meghi shares both a allele 


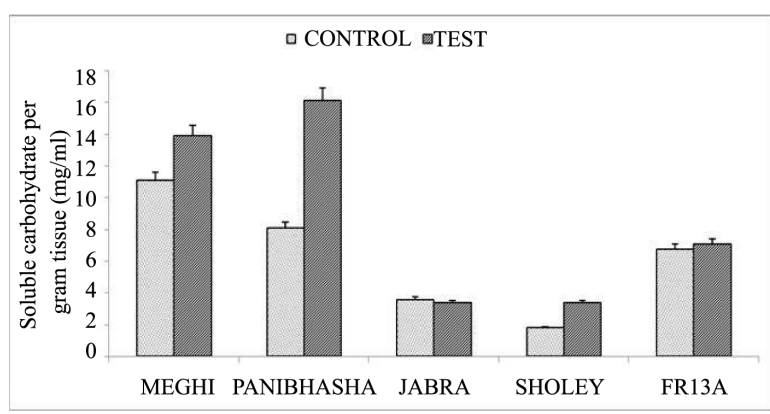

(a)

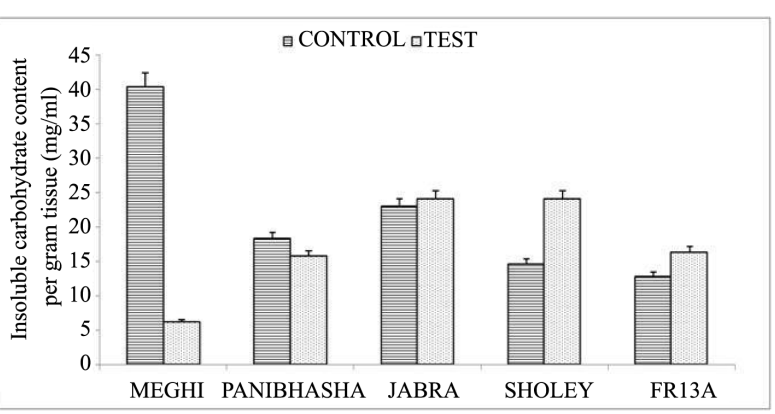

(b)

Figure 6. Graphical presentation of soluble (a) and insoluble (b) carbohydrate content of studied rice lines in submerged (test) and non submerged (control) conditions.

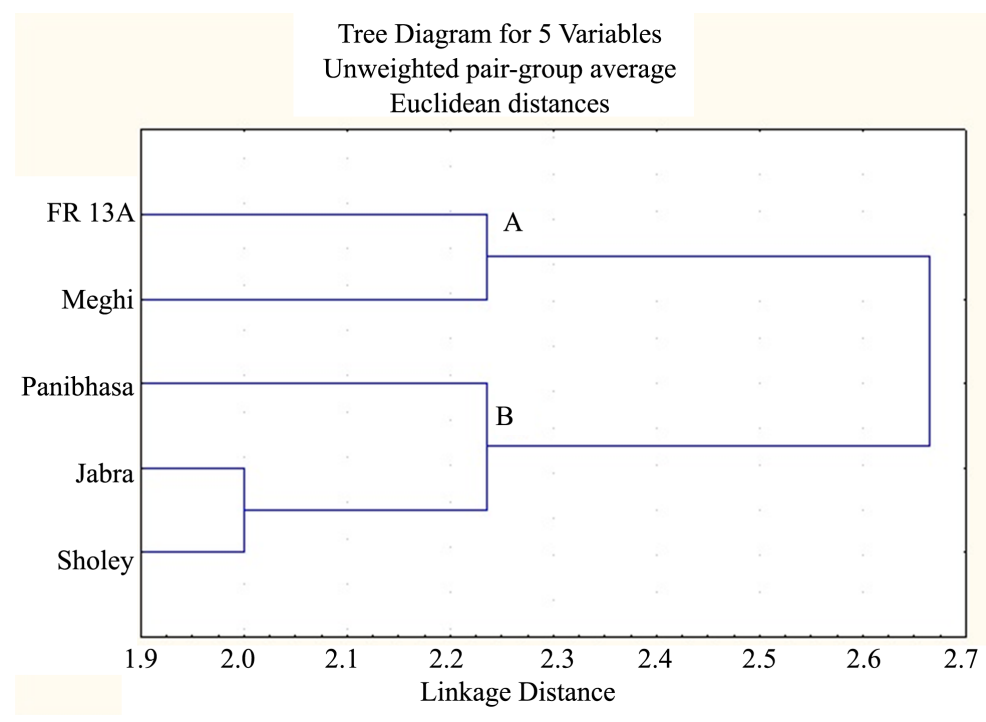

Figure 7. Genotype derived dendrogram showing interrelationship among studied genotypes.

Table 7. PIC value of the studied RM loci.

\begin{tabular}{ccc}
\hline Sl. No. & Marker & PIC Value \\
\hline 1 & RM219 & 0.80 \\
2 & RM464A & 0.96 \\
3 & RM316 & 0.90 \\
4 & RM444 & 0.90 \\
5 & RM285 & 0.93 \\
\hline
\end{tabular}

of FR13A and $\mathrm{a}_{2}$ allele of Panibhasha and Jabra. The remaining genotype, Sholey showed $\mathrm{b}_{1}$ allele of $S u b 1 B$ loci and $\mathrm{c}_{2}$ allele of $\mathrm{Sub} 1 \mathrm{C}$ loci but total absence the $\mathrm{Sub} 1 \mathrm{~A}$ loci.

\section{Discussions}

From this study it had been concluded that the different rice lines investigated in this present study showed differential responses to submergence. In Meghi, Panibhasa and FR13A seedling growth and development checked under submerged condition, whereas in Jabra the seedling growth and development was affected least. In the rest genotype (Sholey), the seedling showed better performance under submerged condition. Statistical test for mean difference in shoot length under normal and test condition showed that Meghi and FR13A shared a com- 
mon performance where non-significant mean difference indicated submergence tolerance whereas significant difference with positive increment in Panibhasa, Jabra and Sholey indicated their long rice nature (submergence escaping properties). Out of these four lines, Meghi showed some unique properties very much parallel to FR13A, a well reported rice line which had been taken as donor plant in a number of submergence tolerance breeding programme and had been introgressed to develop a good number of high yielding submergence tolerant lines (e.g. Swarna-Sub1, IR64-Sub1, Samba Mahsuri-Sub1, etc.). The higher amount of aerenchyma tissue formation with retarded shoot growth under submerged condition indicated its submergence tolerance property (quiescence strategy), very much similar to FR13A whereas continuous growth and insignificant changes of aerenchyma tissue formation under submergence for the rest of the genotypes (Jabra, Sholey and Panibhasha) shared properties of deep water rice. In respect to carbohydrate utilization under submerged condition only Jabra followed deep water properties as in this line amount of soluble carbohydrate decreased with gradual increase of insoluble carbohydrate. Least degradation in chlorophyll content under submergence in Jabra is very significant for its stress tolerant properties in addition to its deep water nature. Though most of the incidence of flooding occurs at late monsoon (post-transplantation time), sometimes seed beds are also affected by early monsoon which results in severe loss of seedlings. Jabra, which shows highest seedling vigor under submerged condition, may be included as a potent tolerant genotype for seedbed flooding and consequent seedling loss. The submergence tolerance property of Meghi was also confirmed through marker based genotyping by sharing with FR13A in derived dendrogram and also sharing of common allele for Sub1A, Sub1B and Sub1C loci. Sharing of another allelic form of $S u b 1 A$ locus respectively by Meghi with Panibhasha and Jabra proves their partial likeness which may result in common sharing of both submergence tolerance and deep water nature. As the in silico study is done on Nipponbare genome (which is the main rice genomic source of Gramene), which is also a known submergence susceptible variety, the presence of $S u b 1 A$ of $950 \mathrm{bp}$ is in keeping with the submergence tolerant varieties (Meghi and FR13A). From this study it can be concluded that both Meghi and Jabra are the potent genetic resources for lowland and flood prone areas having common properties of both submergence tolerance and deepwater nature. Though both of these lines are low yielder with poor grain and kernel quality, they can be used as donor plant for the development of high yielding submergence tolerant and deep water rice through marker assisted breeding programme. From the marker based screening among IR36 and the lines selected to be most potent in this study (Meghi and Jabra), it is revealed (Table 8) that RM 285 may be used as a polymorphic marker for marker assisted selection (MAS) involving submergence tolerance breeding programme. This present investigation may be considered as a baseline study for characterization and utilization of valuable

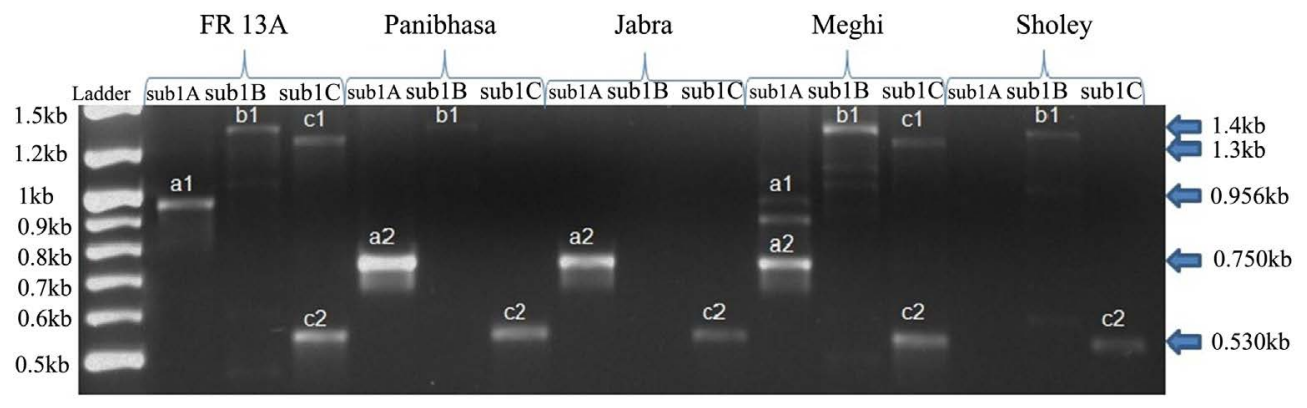

Figure 8. Gel picture showing amplified bands for the Sub1 loci among the studied rice lines.

Table 8. The fingerprint profile.

\begin{tabular}{cccc}
\hline \multirow{2}{*}{ SSRs } & \multicolumn{2}{c}{ Rice genotypes } \\
\cline { 2 - 4 } RM219 & IR36 & Jabra & Meghi \\
RM316 & 245.27 & NA & 236.77 \\
RM464A & 187.68 & 185.36 & NA \\
RM444 & NA $^{*}$ & 246.07 & 261.72 \\
RM285 & NA & NA & 230.36 \\
\hline
\end{tabular}

\footnotetext{
${ }^{*}$ Not Amplified.
} 
unexplored genetic resources through marker assisted breeding programme. In addition to this, the experimented lines and the investigated marker loci may also be used for QTL mapping following development of mapping population targeting Sub1 loci in rice.

\section{Acknowledgements}

Authors are thankful to DBT, Government of India and financial support was provided by DST, Government of India through DST-INSPIRE program.

\section{References}

[1] Sarkar, R.K., Reddy, J.N., Sharma, S.G. and Ismail, A.M. (2006) Physiological Basis of Submergence Tolerance in Rice and Implications for Crop Improvement. Current Science, 91, 899-896.

[2] Adkins, S.W., Shiraishi, T. and McComb, J.A. (1990) Submergence Tolerance of Rice-A New Glasshouse Method for the Experimental Submergence of Plants. Physiologia Plantarum, 80, 642-646. http://dx.doi.org/10.1111/j.1399-3054.1990.tb05691.x

[3] Jackson, M.B. and Ram, P.C. (2003) Physiological and Molecular Basis of Susceptibility and Tolerance of Rice Plants to Complete Submergence. Annals of Botany, 91, 227-241. http://dx.doi.org/10.1093/aob/mcf242

[4] Yamada, N. (1959) Physiological Basis of Resistance of Rice Plant against Overhead Flooding. Bulletin of the National Institute of Agricultural Sciences, 8, 111-112.

[5] Ito, O., Ella, E. and Kawano, N. (1999) Physiological Basis of Submergence Tolerance in Rainfed Lowland Rice Ecosystem. Field Crops Research, 64, 75-90. http://dx.doi.org/10.1016/S0378-4290(99)00052-0

[6] Sarkar, R.K., Das, S. and Ravi, I. (2001) Changes in Certain Antioxidative Enzymes and Parameters as a Result of Complete Submergence and Subsequent Re-Aeration of Rice Cultivars Differing in Submergence Tolerance. Journal of Agronomy and Crop Science, 187, 69-74. http://dx.doi.org/10.1046/j.1439-037X.2001.00510.x

[7] Ella, E.S., Kawano, N., Yamauchi, Y., Tanaka, K. and Ismail, A.M. (2003) Blocking Ethylene Perception Enhances Flooding Tolerance in Rice Seedlings. Functional Plant Biology, 30, 813-819. http://dx.doi.org/10.1071/FP03049

[8] Das, K.K., Sarkar, R.K. and Ismail, A.M. (2005) Elongation Ability and Non-Structural Carbohydrate Levels in Relation to Submergence Tolerance in Rice. Plant Science, 168, 131-136. http://dx.doi.org/10.1016/j.plantsci.2004.07.023

[9] Hattori, Y., Nagai, K. and Ashikari, M. (2011) Rice Growth Adapting to Deep Water. Current Opinion in Plant Biology, 14, 100-105. http://dx.doi.org/10.1016/j.pbi.2010.09.008

[10] Banerjee, S., Dey, N. and Adak, M.K. (2015) Assessment of Some Biomarkers under Submergence Stress in Some Rice Cultivars Varying in Responses. American Journal of Plant Sciences, 6, 84-94. http://dx.doi.org/10.4236/ajps.2015.61010

[11] Xu, K. and Mackill, D.J. (1996) A Major Locus for Submergence Tolerance Mapped on Rice Chromosome 9. Molecular Breeding, 2, 219-224. http://dx.doi.org/10.1007/BF00564199

[12] Xu, K., Xia, X., Fukao, T., Canlas, P., Maghirang-Rodriguez, R., Heuer, S., Ismail, A.M., Bailey-Serres, J., Ronald, P.C. and Mackill, D.J. (2006) Sub1A Is an Ethylene Response Factor-Like Gene That Confers Submergence Tolerance to Rice. Nature, 442, 705-708. http://dx.doi.org/10.1038/nature04920

[13] Xiong, H., Yang, J. and Li, Y. (2012) Identification of Submergence-Responsive Genes in Two Indica Rice Genotypes Carrying $S U B 1 A-1$ but Exhibiting Differential Tolerance. Journal of Plant Biology, 55, 233-241. http://dx.doi.org/10.1007/s12374-011-0315-9

[14] Bailey-Serres, J., Fukao, T., Ronald, P., Ismail, A., Heuer, S. and Mackill, D. (2010) Submergence Tolerant Rice: SUB1's Journey from Landrace to Modern Cultivar. Rice, 3, 138-147. http://dx.doi.org/10.1007/s12284-010-9048-5

[15] Sarkar, R.K. and Bhattacharjee, B. (2011) Rice Genotypes with SUB1 QTL Differ in Submergence Tolerance, Elongation Ability during Submergence and Resubmergence and Regeneration Growth at Reemergence. Rice, 5, 7.

[16] Biswas, T., Das, A. and Bhattacharyya, S. (2012) Microsatellite Marker Based Diversity Analysis for Submergence Tolerance in Some Bengal Landraces of Rice (Oryza sativa L.). Journal of Tropical Agriculture, 50, 67-71.

[17] Khanh, T.D., Linh, L.H., Linh, T.H., Ham, L.H. and Xuan, T.D. (2013) Rapid and High-Precision Marker Assisted Backcrossing to Introgress the SUB1 QTL into the Vietnamese Elite Rice Variety. Journal of Plant Breeding and Crop Science, 5, 26-33. http://dx.doi.org/10.5897/jpbcs12.052

[18] Sarkar, R.K., Reddy, J.N., Das, K.K., Ram, P.C., Singh, P.N., Mazid, M.A., Sommut, W., Pane, H., Sharma, S.G. and Ismail, A.M. (2009) Biophysical Constraints in Flood-Prone Ecosystems: Impacts and Prospects for Enhancing and Sustaining Productivity. In: Haefele, S.M. and Ismail, A.M., Eds., Natural Resource Management for Poverty Reduction and Environmental Sustainability in Fragile Rice-Based Systems, Limited Proceedings, No. 15, International Rice 
Research Institute, Philippines, 67-81.

[19] Neeraja, C.N., Maghirang-Rodriguez, R., Pamplona, A., Heuer, S., Collard, B.C.Y., Septiningsih, E.M., Vergara, G., Sanchez, D., Xu, K., Ismail, A.M. and Mackill, D.J. (2007) A Marker-Assisted Backcross Approach for Developing Submergence-Tolerant Rice Cultivars. Theoretical and Applied Genetics, 115, 767-776. http://dx.doi.org/10.1007/s00122-007-0607-0

[20] Singh, S., Mackill, D.J. and Ismail, A.M. (2009) Responses of SUB1 Rice Introgression Lines to Submergence in the Field: Yield and Grain Quality. Field Crops Research, 113, 12-23. http://dx.doi.org/10.1016/j.fcr.2009.04.003

[21] Iftekharuddaula, K.M., Newaz, M.A., Salam, M.A., Ahmed, H.U., Mahbub, M.A.A., Septiningsih, E.M., Collard, B.C.Y., Sanchez, D.L., Pamplona, A.M. and Mackill, D.J. (2011) Rapid and High-Precision Marker Assisted Backcrossing to Introgress the SUB1 QTL into BR11, the Rainfed Lowland Rice Mega Variety of Bangladesh. Euphytica, 178, 83-97. http://dx.doi.org/10.1007/s10681-010-0272-2

[22] Das, T. and Das, A.K. (2014) Inventory of the Traditional Rice Varieties in Farming System of Southern Assam: A Case Study. Indian Journal of Traditional Knowledge, 13, 157-163.

[23] Lang, N.T., Tao, N.V. and Buu, B.C. (2011) Marker-Assisted Backcrossing (MAB) for Rice Submegence Tolerance in Mekong Delta. Omonrice, 18, 11-21.

[24] Manangkil, O.E., Vu, H., Yoshida, S., Mori, N. and Nakamura, C. (2008) A Simple, Rapid and Reliable Bioassay for Evaluating Seedling Vigor under Submergence in Indica and Japonica Rice (Oryza sativa L.) Euphytica, 163, $267-274$. http://dx.doi.org/10.1007/s10681-008-9645-1

[25] Yamauchi, M. and Winn, T. (1996) Rice Seed Vigor and Seedling Establishment in Anaerobic Soil. Crop Science, 36, 680-681. http://dx.doi.org/10.2135/cropsci1996.0011183X003600030027x

[26] Sadasivam, S. and Manikam, A. (2010) Biochemical Methods. Third Print, New Age International, New Delhi.

[27] Arnon, D.I. (1949) Copper Enzymes in Isolated Chloroplasts, Polyphenoxidase in Beta vulgaris. Plant Physiology, 24, 1-15. http://dx.doi.org/10.1104/pp.24.1.1

[28] Lodha, T., Karmakar, J., Roychoudhuri, R. and Dey, N. (2011) Assessment of Genetic Diversity of Some Commonly Grown Rice Genotypes of South Bengal Using Microsatellite Markers Associated with the Saltol QTL Mapped on 1st Chromosome. NBU Journal of Plant Sciences, 5, 35-39.

[29] Karmakar, J., Roychowdhury, R., Kar, R.K., Deb, D. and Dey, N. (2012) Profiling of Selected Indigenous Rice (Oryza sativa L.) Landraces of Rarh Bengal in Relation to Osmotic Stress Tolerance. Physiology and Molecular Biology of Plants, 18, 125-132.

[30] Ganie, S.A. and Mondal, T.K. (2015) Genome-Wide Development of Novel miRNA-Based Microsatellite Markers of Rice (Oryza sativa) for Genotyping Applications. Molecular Breeding, 35, 51. http://dx.doi.org/10.1007/s11032-015-0207-7

[31] Peng, B., Wang, L., Fan, C., Jiang, G., Luo, L., Li, Y. and He, Y. (2014) Comparative Mapping of Chalkiness Components in Rice Using Five Populations across Two Environments. BMC Genetics, 15, 49. http://dx.doi.org/10.1186/1471-2156-15-49

[32] Sambrook, J. and Russell, D.W. (2001) Molecular Cloning: A Laboratory Manual. 3rd Edition, Cold Spring Harbor, New York, 5.42-5.46.

[33] Hwang, T.Y., Sayama, T., Takahashi, M., Takada, Y., Nakamoto, Y., Funatsuki, H., et al. (2009) High-Density Integrated Linkage Map Based on SSR Markers in Soybean. DNA Research, 16, 213-225. http://dx.doi.org/10.1093/dnares/dsp010 